\title{
The incidence and position of melanocytic nevi for the purposes of forensic image comparison
}

\author{
S. Black • B. MacDonald-McMillan • X. Mallett • \\ C. Rynn • G. Jackson
}

Received: 6 November 2012 / Accepted: 4 January 2013 / Published online: 19 February 2013

(C) The Author(s) 2013. This article is published with open access at Springerlink.com

\begin{abstract}
Expert witness opinion based on the comparison of images has been accepted by UK courts as admissible evidence in relation to issues of identity. Within images of the hand are a multiplicity of anatomical features of different aetiology, incidence and distribution patterns and this includes melanocytic nevi, referred to more colloquially as moles and/or birthmarks. The hand is not a common place for these isolated features to develop and so their presence in this anatomical region has the potential to be useful for issues of identity. The results of this study show that approximately $9 \%$ of individuals in a sample of 476 hands, displayed at least one nevus on the back of their hand and, contrary to the literature, the incidence was found to be greater in females $(15 \%$ of female cohort) than males ( $7 \%$ of male cohort). Almost a third of all nevi identified on the dorsum of the hand were abnormal or dysplastic. The most frequent location for these aggregations of melanocytes was in the central region of the dorsum of the hand or at the base of the index finger. The relevance of nevi identified in the image of a perpetrator's hand and also on that of a suspect/accused is discussed in relation to the issue of whether the images have originated from the same individual.
\end{abstract}

Keywords Melanocytic nevi $\cdot$ Hand $\cdot$ Image comparison

\section{Introduction}

Melanocytic nevi are more commonly referred to as 'moles' or 'birthmarks' and are by definition benign neoplasms, although $50 \%$ of malignant melanomas are said to arise

S. Black $(\bowtie) \cdot$ B. MacDonald-McMillan $\cdot$ X. Mallett $\cdot$ C. Rynn University of Dundee, Dundee, UK

e-mail:s.m.black@dundee.ac.uk

G. Jackson

University of Abertay, Dundee, UK from pre-existing nevi [1]. Nevi are reported to be present in approximately $1-2 \%$ of newborns although they also develop later in childhood when they are referred to more correctly as 'tardive' or congenital nevi [2-5]. It is also possible for nevi to develop in older individuals and they are then referred to as common 'acquired' melanocytic nevi.

Congenital and common acquired melanocytic nevi are clinically indistinguishable. Generally, they possess a regular, smooth and well-demarcated border, which tends to be round or oval $[6,7]$. Their colouration is commonly a uniform pale to dark brown or black and can be accompanied by long, course and darkly pigmented hairs although this is less common in areas such as the hand [3]. Abnormal nevi are moles that do not match the regularity of appearance described above; they can be asymmetrical in shape, with an irregular border, be of varying colour across the nevus and they usually have a diameter in excess of $6 \mathrm{~mm}$ [7]. According to the National Cancer Institute, these abnormal moles are more likely to develop into melanomas (skin cancer) [8,9].

The factors that most influence the development of nevi are debated, but when they are present at birth this obviously supports a strong genetic predisposition for the formation of these nested, melanin producing cellular aggregations in the stratum basale of the epidermis [10]. Although a genetic component is most probably still influential for congenital and common acquired nevi, it has been suggested that these may also be influenced by exposure to ultraviolet radiation and this is supported in part by the observation that they are more commonly found in exposed areas of the skin including the face, neck, upper trunk and arms [11-13]. Green and Swerdlow [10] have suggested that they are more frequent in the limbs of lighter-skinned individuals but are more common on the neck, face, and torso of darker skinned individuals.

Numbers of nevi are reported to increase from birth to early adulthood, peaking at around 25 years $[10,14]$. Johr and Schachner [14] suggested that a full body count of 43 nevi 
for a male and 27 for a female by 25 years of age would be considered normal, in individuals who are predisposed to nevus formation. Nevi are reported to undergo gradual shrinkage and fading with time and have been reported to have all but disappeared by 80 years of age [14-17]. In a study by Kennedy et al. [18], age was reported to be the strongest influencing factor in the decline of both normal and atypical nevi numbers, with periods of chronic sun exposure showing no observable effect on their reduction in incidence. However, caution has been advocated as the observed decline in nevus number with age may also represent an effect of secular or temporal change. An example given by Kennedy et al. [18] describes how 13- to 15year-old children born in 1977 and 1978 had a 5- to 6-fold higher prevalence of nevi than a comparable cohort born two decades earlier suggesting possibly that it is more common today than it has been in the past, perhaps due to increased levels of radiation exposure and subsequent skin response [19].

The incidence and prevalence of nevi is reported to be highest in younger age groups and in males. Darlington et al. [12] followed a cohort of children over a 5-year period and found that the mean number of nevi increased year on year from the age of 12 to 17 years, with males always possessing a higher count than females. This was the case in full body counts as well as region-specific counts. Some authors suggest that nevus numbers may plateau around puberty $[12,20]$ although others suggest a much later peak age [17].

Harrison et al. [13] reported that nevi on the hands were less common than on other frequently sun-exposed areas such as the forearms, upper arms and neck and this was supported by the results of the study by English and Armstrong [20], who undertook a nevus count on school children from Perth, Western Australia. Not surprisingly, it was also noted that nevi were seen more frequently on the dorsum of the hand than on the palmar surface as is true of most pigment-related dermatological features including ephilides (freckles) and lentigines (liver spots) [21-23].

The presence of nevi on the dorsum of the hand has been utilised as a feature for consideration within the multifactorial process of hand image comparison. Within the Centre for Anatomy and Human Identification (CAHID) at the University of Dundee, image comparisons are undertaken of the anatomical features of the dorsum of the hand for the purposes of comparing offender images to images of a suspect/accused or indeed for comparing images of a victim to images of a suspected victim. In the majority of cases, these involve images of child sexual abuse where the dorsum of the hand of the perpetrator is visible. The sharing of images of child pornography is recognised as one of the fastest growing crimes of modern times $[24,25]$ with close to a million new photographs being posted on the Internet daily. The ease of access to the World Wide Web and an increasing array of digital recording devices is of concern to the law enforcement profession, as the sharing of images and the demand that this has generated, has added a new dimension to the social problem of child protection and the investigation and prosecution of child exploitation and sexual offenses [26-29].

It is essential that an understanding of the incidence and most common location of nevi on the dorsum of the hand is more fully understood if it is to be used for the purposes of interpreting image comparison in relation to issues of identity. Therefore the aim of this research was to record the incidence and position of nevi on the dorsum of the hand from a series of standardised photographic images and to assess, through an evaluation of likelihood ratios, the potential evidential weight of such features.

\section{Material and methods}

The CAHID holds a database of standardised high-quality photographic images of the dorsum of the hand. At the time of this research, the database comprised 260 individuals for whom images were available of the dorsum of both their right and left hand. Using only the participants who gave permission for personal information including sex and hand dominance to be recorded, resulted in a total sample of 238 individuals (476 hands) comprised of 177 males and 61 females (Table 1). The age range for the sample was 21-62 years with a mean age of 43 years. As per the expected incidence, approximately $10 \%$ of the sample was left-handed and $90 \%$ was right-handed. As far as could reasonably be determined, all individuals were of Caucasian ancestry. Any individual with digital amputations was not included nor were any individuals with developmental or congenital physical deformities of the hand.

Twenty seven landmarks were selected to permit construction of a deformation grid and they were chosen for their anatomical stability and visibility in all images (Table 2). The dorsal surface of each hand image was divided into 24 cells by the grid defined by the landmarks and each cell was assigned an identification number (Fig. 1). Once each hand was grid mapped, the presence and location of a nevus was recorded for both the right and left hand of each individual (Fig. 2).

The number of nevi was a simple count of those present within an image and within each cell of the grid. If a nevus was sufficiently large to cross a grid line, then it was recorded within the grid where the majority of the pigmentation resided. Therefore, no nevus was counted twice. The incidence and location of abnormal nevi was also recorded.

Table 1 Sample separated according to hand dominance and sex

\begin{tabular}{lcccr}
\hline & Right handed & Left handed & Ambidextrous & Total \\
\hline Male & 156 & 21 & 0 & 177 \\
Female & 55 & 5 & 1 & 61 \\
Total & 211 & 26 & 1 & 238 \\
\hline
\end{tabular}


Table 2 Definition of the points that permit construction of the hand grid

\begin{tabular}{|c|c|}
\hline \multicolumn{2}{|c|}{ Landmark } \\
\hline 1 & Most medial point on wrist constriction \\
\hline 2 & Most lateral point on wrist constriction \\
\hline 3 & Deepest point in the interdigital webbing between digits 1 and 2 \\
\hline 4 & Most lateral and prominent point over the first metacarpophalangeal (MCP) joint \\
\hline 5 & Deepest point in the interdigital webbing between digits 2 and 3 \\
\hline 6 & Deepest point in the interdigital webbing between digits 3 and 4 \\
\hline 7 & Deepest point in the interdigital webbing between digits 4 and 5 \\
\hline 8 & Medial border of the base of digit 5 parallel to the MCP joint \\
\hline 9 & Lateral border of base of digit 2 parallel to the MCP joint \\
\hline 10 & Medial border of thumb parallel to the interphalangeal (IP) joint \\
\hline 11 & Lateral border of the thumb parallel to the IP joint \\
\hline 12 & Medial border of digit 5 parallel to the proximal interphalangeal (PIP) joint \\
\hline 13 & Lateral border of digit 5 parallel to the PIP joint \\
\hline 14 & Medial border of digit 4 parallel to the PIP joint \\
\hline 15 & Lateral border of digit 4 parallel to the PIP joint \\
\hline 16 & Medial border of digit 3 parallel to the PIP joint \\
\hline 17 & Lateral border of digit 3 parallel to the PIP joint \\
\hline 18 & Medial border of digit 2 parallel to the PIP joint \\
\hline 19 & Lateral border of digit 2 parallel to the PIP joint \\
\hline 20 & Medial border of digit 5 parallel to the distal interphalangeal (DIP) joint \\
\hline 21 & Lateral border of digit 5 parallel to the DIP joint \\
\hline 22 & Medial border of digit 4 parallel to the DIP joint \\
\hline 23 & Lateral border of digit 4 parallel to the DIP joint \\
\hline 24 & Medial border of digit 3 parallel to the DIP joint \\
\hline 25 & Lateral border of digit 3 parallel to the DIP joint \\
\hline 26 & Medial border of digit 2 parallel to the DIP joint \\
\hline 27 & Lateral border of digit 2 parallel to the DIP joint \\
\hline
\end{tabular}

The results of this study were then considered in the light of a recent case of child sexual abuse where the offender and the accused both displayed clearly defined abnormal areas of skin pigmentation on the dorsum of the hand.

An evaluation of the evidential weight of scars on hands has previously been described by Jackson and Black [30] who based their approach, as recommended by the Association of Forensic Science Providers [31], on an assessment of a likelihood ratio. The approach presented by Jackson and Black [30] provides a general model that can be applied to all cases involving the use of features in hand images to help address issues of identity.

Following their notation, the likelihood ratio provided by the observation of features in hand images can be written as:

$\mathrm{LR}=\frac{\operatorname{Pr}\left[\mathrm{O}_{\mathrm{C}} \mid \mathrm{O}_{\mathrm{D}}, \mathrm{H}_{\mathrm{P}}, \mathrm{F}_{\mathrm{C}}, \mathrm{F}_{\mathrm{D}}\right]}{\operatorname{Pr}\left[\mathrm{O}_{\mathrm{C}} \mid \mathrm{H}_{\mathrm{D}}, \mathrm{F}_{\mathrm{C}}\right]}$

where:

$O_{\mathrm{C}}$ denotes the observations from the offender's image

$O_{\mathrm{D}}$ denotes observations from the suspect/accused's image
$F_{\mathrm{C}}$ represents the circumstances surrounding the incident, including evidence about the nature of the true offender and the recording conditions of the questioned images

$F_{\text {D }}$ represents the circumstances surrounding the accused, including the time interval between the incident and the suspect/accused's images being taken

$H_{\mathrm{P}}$ the image is that of the hand of the suspect/accused

$H_{\mathrm{D}}$ the image is that of the hand of some other, unknown person

\section{Results}

Table 3 shows that a total of 34 nevi were detected in 21 individuals - this equated to an incidence of approximately $9 \%$ across the whole cohort who possessed at least one nevus on the dorsum of their hand. Eighteen nevi were found in the hands of 12 males $(7 \%$ of the male cohort displayed at least one nevus) and 16 were found in the hands of nine females ( $15 \%$ of the female cohort displayed at least one nevus). Whilst equal numbers were found in female 


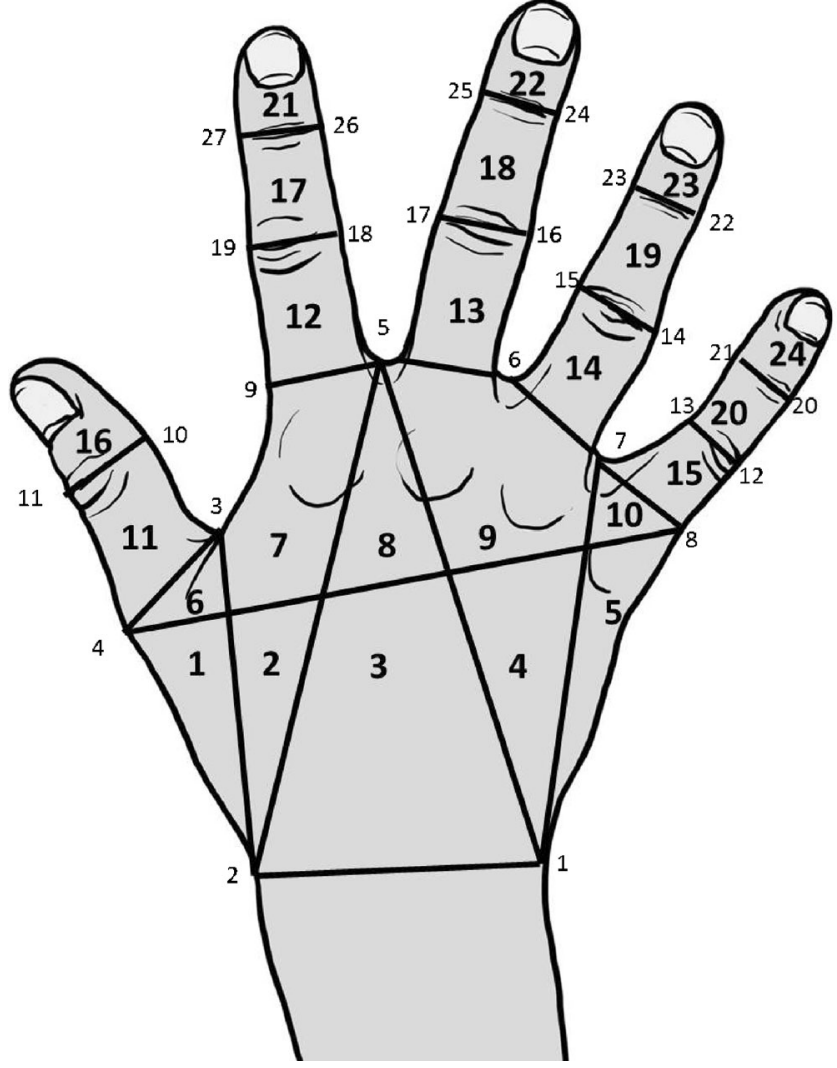

Fig. 1 Location of the 27 hand landmarks and the formation of the deformation grid that arises from these to result in 24 grid cells for recording purposes

right and left hands (eight in each), 13 were found in the male right hand and only five in the male left hand. It was most common in both males and females for there to be only one nevus present in either hand (seven females and nine males), but multiple presentations did occur with two nevi being found in one male, three in one male, four in both a male and a female and five being the maximum number found in any one individual, which were present in a female where four occurred on the right hand and one on the left.

Out of the 34 nevi identified, ten (almost a third) were classified as atypical. These were found in six individuals (three males and three females) who displayed other normal nevi on the dorsum of their hand. Four out of the six individuals (two males and two females) showed only one abnormal nevus while one female possessed two on her right hand and one male individual had a total of four abnormal nevi (three on the right and one on the left).

Figure 3 shows that nevi are most frequently located across the flat plate of the dorsum of the hand and rarely in a location more distal than the proximal interphalangeal joint. Grid cells 3 and 7 were the most common location for nevi, and grid cell 3 was the only one to show a nevus in both the right and left hands of both males and females. Nevi were not found in either hand of either sex associated with the small finger or the area of the medial border of the hand associated with it (grid cells 5, 10, 15, 20 and 24) and only one nevus was found distal to the proximal interphalangeal joints in a male right hand.

\section{Case}

\section{Relevant case circumstances}

Video and still images were retrieved from an electronic device belonging to a man suspected of committing an
Fig. 2 Image from the database of the left hand of a female participant. A nevus is clearly visible in the grid cell 3 region of the hand

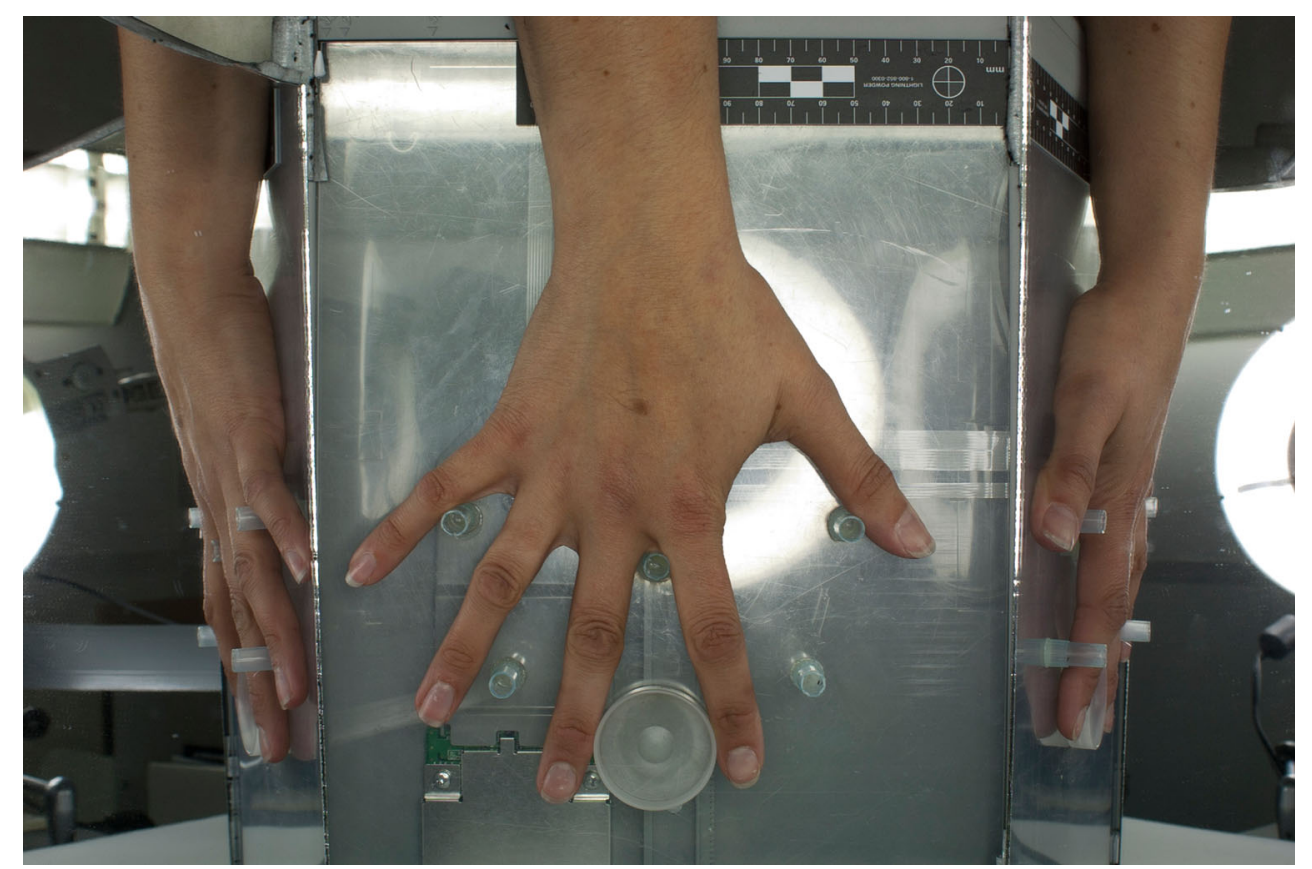


Table 3 Incidence of nevi in male and female right and left hands in each of the 24 grid cells

\begin{tabular}{|c|c|c|c|c|c|}
\hline \multirow[t]{2}{*}{ Cell no. } & \multicolumn{2}{|l|}{ Male } & \multicolumn{2}{|c|}{ Female } & \multirow[t]{2}{*}{ Tota } \\
\hline & Right & Left & Right & Left & \\
\hline 1 & 1 & 0 & 0 & 1 & 2 \\
\hline 2 & 0 & 0 & 2 & 1 & 3 \\
\hline 3 & 3 & 1 & 1 & 2 & 7 \\
\hline 4 & 0 & 0 & 1 & 0 & 1 \\
\hline 5 & 1 & 0 & 0 & 0 & 1 \\
\hline 6 & 0 & 0 & 0 & 0 & 0 \\
\hline 7 & 2 & 1 & 2 & 0 & 5 \\
\hline 8 & 1 & 0 & 1 & 0 & 2 \\
\hline 9 & 1 & 1 & 0 & 1 & 3 \\
\hline 10 & 0 & 0 & 0 & 0 & 0 \\
\hline 11 & 0 & 1 & 0 & 1 & 2 \\
\hline 12 & 1 & 0 & 0 & 0 & 1 \\
\hline 13 & 1 & 0 & 1 & 0 & 2 \\
\hline 14 & 1 & 1 & 0 & 1 & 3 \\
\hline 15 & 0 & 0 & 0 & 0 & 0 \\
\hline 16 & 0 & 0 & 0 & 1 & 1 \\
\hline 17 & 0 & 0 & 0 & 0 & 0 \\
\hline 18 & 0 & 0 & 0 & 0 & 0 \\
\hline 19 & 1 & 0 & 0 & 0 & 1 \\
\hline 20 & 0 & 0 & 0 & 0 & 0 \\
\hline 21 & 0 & 0 & 0 & 0 & 0 \\
\hline 22 & 0 & 0 & 0 & 0 & 0 \\
\hline 23 & 0 & 0 & 0 & 0 & 0 \\
\hline 24 & 0 & 0 & 0 & 0 & 0 \\
\hline Total & 13 & 5 & 8 & 8 & 34 \\
\hline
\end{tabular}

indecent assault on a child. The images showed what was subsequently confirmed as the right hand of a lightskinned, adult male (determined from other aspects of the images) touching the genital region of a child. The suspect was a middle-aged male with light coloured skin who denied being the person present in the image. The time difference between the two sets of images was no more than a year. The images were recorded in a domestic setting with reasonable light conditions but the recording device produced an image that was of relatively poor quality. He was charged with the offence of indecent assault on a child.

\section{Case assessment}

The fact in issue in this case was whether the images were those of the accused. Propositions to address this issue were generated from the accused's declaration and from the inference that the images of the offender depicted the right hand of a light-skinned, adult male:

$H_{\mathrm{P}} \quad$ the images are of the right hand of the accused

$H_{\mathrm{D}}$ the images are of the right hand of some other, unknown, light-skinned, adult male

To avoid any risk of 'observer bias', the images from the offender were examined prior to those of the accused and any nevi, or possible nevi, were recorded. A period of several days occurred between viewing the images of the offender and those of the accused.

Technical issues

Images were enhanced using Adobe Photoshop CS5. The yellow channel was isolated, which produced a greyscale (monochrome) image that effectively displayed the amount of yellow in the original image: areas of isolated pigmentation contain more yellow than the surrounding skin, so are displayed as darker areas. Subsequent enhancement using the 'levels' tool optimised the contrast between the darker (yellower) patches and the lighter (less yellow) areas. This process was carried out on both the offender image and the images of the accused (Fig. 4).

\section{Results and interpretation}

Several areas of isolated pigmentation were identified in the offender image and one in particular showed the classic appearance of an abnormal nevus. A corresponding area was seen in the accused's image. These areas can be seen encircled in Fig. 5 with the area of abnormal pigmentation being located in grid cell 7. Comparison of the images showed not only the abnormal area of pigmentation encircled with a continuous black line but also a possible second nevus outlined by a broken line which is located in grid cell 9. Other features of similarity were found between the right hand of the accused and the offender but for the purposes of this communication only the information relating to the nevi is addressed.

The observations $\left(O_{\mathrm{C}}\right)$ from the image of the offender consist of

1. A nevus in grid cell 7

2. A possible nevus in grid cell 9

3. The absence of nevi anywhere else on the remainder of the surface of the hand

Ideally, each of these three observations would be assessed separately and sequentially, conditional on the preceding observation. For the purposes of this paper, which seeks only to establish an initial conceptual 
Fig. 3 Location of grid cells that contained a nevus on the dorsum of the hand in right and left hands of males and females
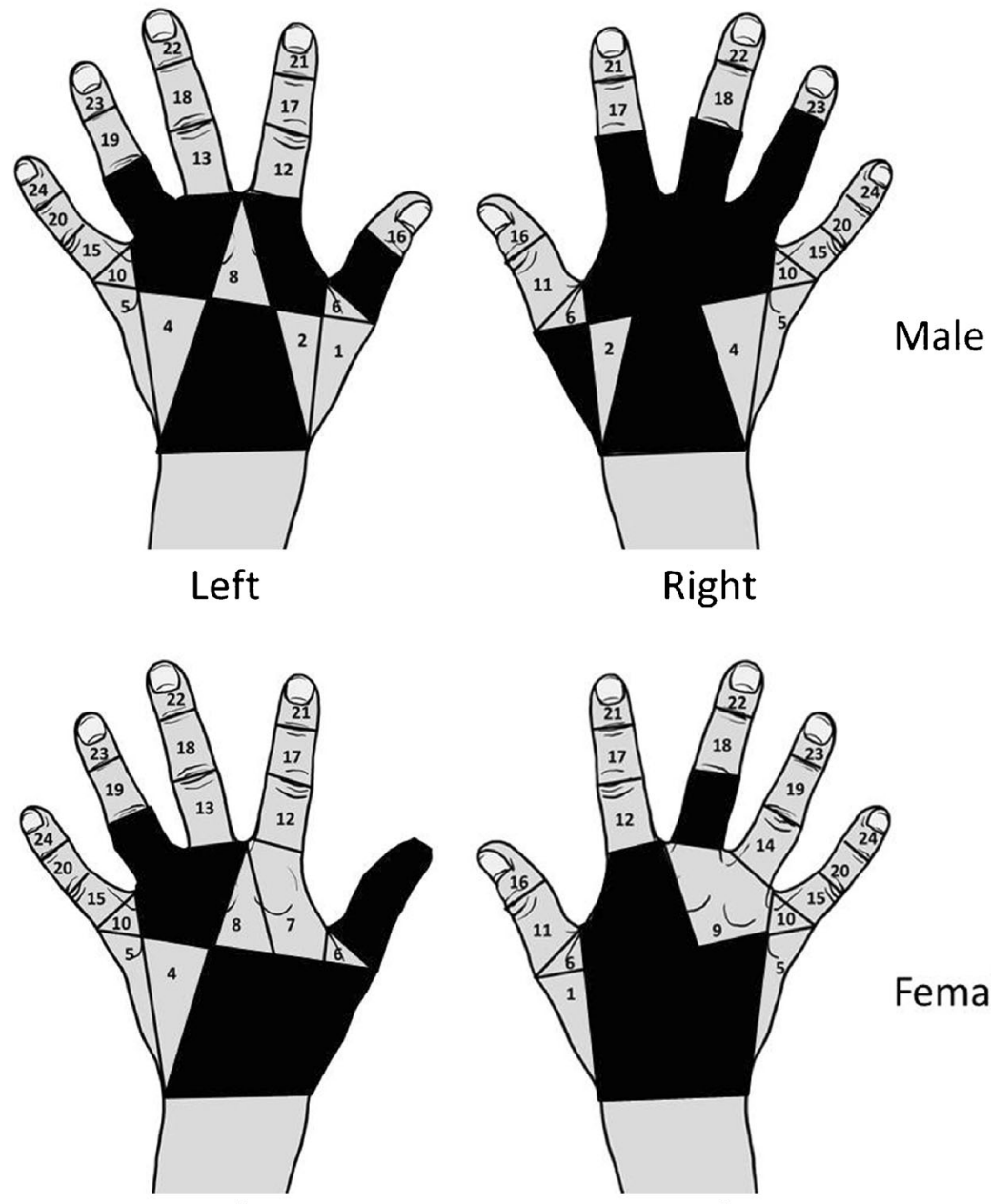

Left

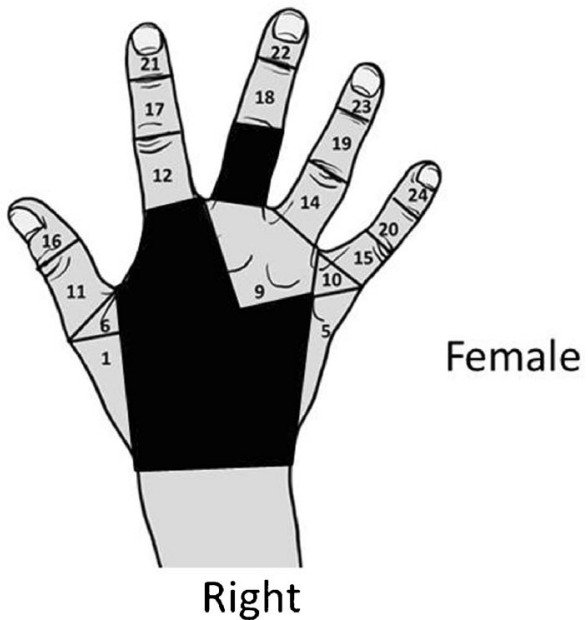

framework, we intend to view the three observations as a single entity $\left(O_{\mathrm{C}}\right)$.

Considering, firstly, the numerator of the likelihood ratio, $\operatorname{Pr}\left[O_{\mathrm{C}} \mid O_{\mathrm{D}}, H_{\mathrm{P}}, F_{\mathrm{C}}, F_{\mathrm{D}}\right]$, what is required is an assessment of the probability that the offender images would appear as they do $\left(O_{\mathrm{C}}\right)$, given that the images are of the accused $\left(H_{\mathrm{P}}\right)$ and given what we know about the time intervals and quality of the images $\left(F_{\mathrm{C}}, F_{\mathrm{D}}\right)$. It would seem reasonable to assign a value approaching 1 for this probability. The images are what the expert expected if they were of the accused.

Looking now at the denominator, $\operatorname{Pr}\left[O_{\mathrm{C}} \mid H_{\mathrm{D}}, F_{\mathrm{C}}\right]$, the required probability is an assessment of the uncertainty of obtaining the observations $\left(O_{\mathrm{C}}\right)$ if the offender's images
Fig. 4 Forensic case enhanced images of the accused's and the offender's right hand

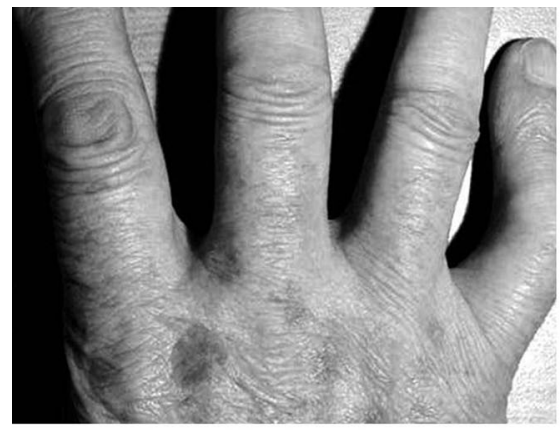

Accused right hand



Offender right hand 
Fig. 5 Forensic case enhanced images of the accused's and the offender's right hand with the position of a nevus outlined in a solid black circle and a second nevus outlined by a broken black circle



Accused right hand

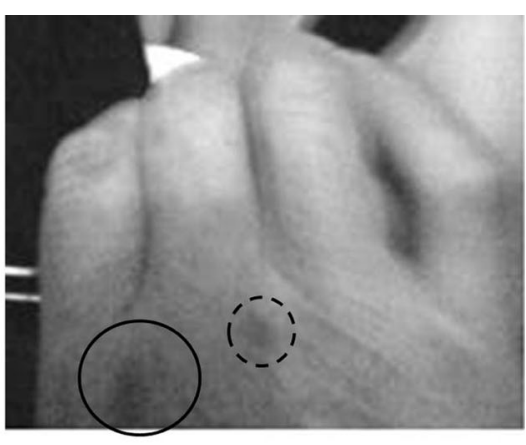

Offender right hand were not those of the accused's right hand but were those of the right hand of another, light-skinned, adult male $\left(H_{\mathrm{D}}\right)$. A key issue then is - what data and knowledge would help the expert to assign a reliable and robust value to this probability? It would seem that some measure of the relative frequency of occurrence of features would be helpful in this respect. While the expert could rely on experience of looking at a large number of hand images to assess frequencies, the potential problems of poor memory and poor recall on the part of the expert could prevent the expert from forming a reliable view on the frequency of occurrence of features. In contrast, relevant databases provide a more transparent, more robust means of assessing frequencies of occurrence. For the denominator in this case, the population under consideration is that of light-skinned, adult males. The database described earlier would provide a reasonable estimate of the frequency of occurrence of the features in such a population, and would thereby inform the expert's probability of observing the features if the images were of some other, light-skinned, adult male. It needs to be remembered, however, that the images within the dataset were obtained using optimal lighting conditions, and were of good resolution, whereas the offender images, having been taken in ambient lighting and using a mobile recording device, were of lower quality. It may be that very weak nevi seen in the reference database would not be visible in hands photographed under less optimal conditions. Caution therefore needs to be exercised when assessing frequencies from databases and allowances should be made for lighting and image quality.

If we consider initially the nevus in grid cell 7 , then the frequency of occurrence of such a feature in the database is 2/177 light-skinned, adult, male right hands, or 0.011 . Neither of these two individuals had nevi elsewhere on their right hands. Only one individual in the database showed a nevus in cell 9 and this individual had no other nevi on his right hand. The relative frequency for this feature would then be $1 / 177$, or 0.0056 . It seems reasonable then to assign a value of 0.011 for the probability of observing a nevus in cell 7 and a probability value of 0.0056 for a nevus in cell 9 . It would be tempting to multiply together these two figures to provide a probability for the joint occurrence of these two features. However, this can only be sanctioned through the assessment of conditional probabilities that take into account any dependency of the occurrence of one feature on the occurrence of a second feature. For the purposes of this case study, the observations are being considered as a single entity $\left(O_{\mathrm{C}}\right)$ and the joint occurrence of the three features - a nevus in cell 7, a nevus in cell 9 and none elsewhere on the hand - can be assessed by interrogation of the database for the occurrence of the combination of the three. In this way, any dependency is automatically being accommodated. On interrogation of the database, no individual was found who possessed these three features together - the frequency of occurrence is zero.

As reported by Jackson and Black [30], there are various ways of estimating a relative frequency of occurrence of features that have not been seen within datasets. Curran et al. [32] reviewed several methods in relation to DNA profiling and concluded that a method known as 'size-bias correction' provided an acceptable, easily calculated and readily understood approximation for these frequencies. Jackson and Black [30] described the application of this method to assessing relative frequencies of scars on hands. Following this method, and on the basis that the previously unseen combination of features has now occurred, the case-specific instances are simply added to the dataset. However, it is not just a single instance that is added to the database; two instances must be added. The probability under consideration is the denominator. The condition of the denominator is that the offender and the accused are not the same person. There are therefore two people who have now been seen with this combination of features, and there are therefore two instances that have to be added to the dataset. The relative frequency of occurrence of the combination would then become 2 in 179 (177 right hands, plus two 'new' right hands), or $1.1 \%$. If this is accepted as a reasonable and robust estimate of the relative frequency of occurrence, then a value of 0.011 could be assigned to the probability of obtaining this feature if the offender's hand image was that of some other unknown, light-skinned, adult male and not that of the accused. 
Substituting these values for the numerator and denominator in Eq. 1 gives an LR of 90. In Bayesian terms, an LR of 90 increases the prior odds of the image being that of the accused by a factor of 90 . Illustrations of the impact of such a value were given in Jackson and Black [30]. An alternative way of expressing the LR is through use of a verbal scale, based on the log of the LR, to convey the weight of evidence in support of one proposition over another. An LR of 90 is towards the upper end of the category $10<\mathrm{LR}<100$ which has been described in the AFSP standard [31] as 'moderate' support.

If the expert was also to take into account the size and shape of nevi, and not just their presence, then it would seem to be justified to say LRs would be significantly greater than those assigned solely from the occurrence of nevi. An example involving scars on hands is given by Jackson and Black [30]. Their illustration showed how the likelihood ratio provided by the presence of two scars on the hand could be increased by a factor of approximately 16 , from 90 to 1,450 , if orientation and size of scars was also taken into account in the evaluation. Depending on which extra metrics of nevi were evaluated, it may be possible to increase the LRs provided by such features by one or two orders of magnitude. However, as these LRs would be based on denominator probabilities of the order $1 / 1,000$ to $1 / 10,000$ (in turn, based on relative frequencies of $1 / 1,000$ to $1 / 10,000$ ), large databases would be required in order to justify such low probabilities [33].

\section{Reporting}

There are several ways in which the LR value could be reported. One way would be to state the value of the LR:

In my opinion, the observations in the images of the offender would be approximately 90 times more likely to be obtained if the images were of the accused's right hand rather than of the right hand of another, unknown, light-skinned adult male.

Another way to express an evaluative opinion, based on an LR of between 10 and 100, would be in the form recommended by the AFSP [31]:

The observations in this case provide moderate support for the proposition that the image is of the right hand of the accused rather than of the right hand of some unknown, light-skinned, adult male.

\section{Discussion}

Moles, birthmarks and other anomalies of the skin have been consigned in the past to 'witches marks', being considered to be a branded sign of the devil to indicate subservience and obedience [34]. In the 300 years between 1450 and 1750 , over 35,000 people, mostly women, were executed and the mark that often sealed their fate was an aggregation of melanocytes in their epidermis. If, when the mole was lanced with a pin, the accused did not bleed or feel pain then it was deemed irrefutable evidence of their pact with the devil. Moles, or nevi, today are still regarded with suspicion but not as some superstitious demonic symbol but as a potential precursor for skin cancer [16]. Benign melanocytic nevi are common and it is generally accepted that most adults will have between ten and 40 distributed across their entire body, the majority of which will gradually fade with age [10]. The hand is not a common place for them to develop and so their presence in this anatomical region has the potential to be useful for the purposes of image comparison.

In the case described, there were other indicators of identity present on the hand but based on the incidence of the nevi alone, this feature provides at least 'moderate' support $(10<\mathrm{LR}<100)$ for the proposition that the image was that of the accused rather than of another, unknown, light-skinned, adult male. If other aspects of the nevus, such as size and shape were to be taken into account, and if the occurrence of two features are accepted as being independent of each other, then the evidence could provide 'strong' support $(1,000<\mathrm{LR}<10,000)$ for that proposition.

It is generally accepted that the propensity towards developing nevi will be genetically influenced and can be enhanced by exposure to ultraviolet radiation, but there is no suggestion within the literature that the location of a nevus is controlled, only the possibility that one may develop. Therefore, melanocytic nevi may be potentially important indicators of human variability when comparing images for the purposes of issues pertaining to identity.

The results from this study suggest that females are twice as likely as males to display a nevus on the back of their hand. Almost a third of these are likely to be abnormal and therefore the irregularity of the outline may also prove to be an important characteristic for identification purposes providing the images are of sufficient quality to permit tracing which was not the situation for the case described in this communication. Men are more likely to show nevi on the right than their left hands, a characteristic not seen in the females in this sample and when nevi are present then they are most likely to occur at the base of the index finger and in the flat plate of the dorsum of the hand just distal to the wrist.

Although the study cohort was of a reasonable size for a pilot investigation into the value of nevi for image comparison, further data requires to be collected as the demographic was heavily skewed towards white males between the ages of 20 and 45 years. Whilst this may be a realistic proxy 
for a paedophile profile, it is not representative of the wider population and therefore a much wider study is required on a significantly enhanced data set which includes a larger number of females and individuals of greater ethnic diversity. It is important, as intimated in the Law Commission report [35], that novel and developing techniques should not be discouraged from presentation to the court providing the evidence is supported by appropriate research validation. Quantification of results and substantiation of conclusions drawn using data is becoming an ever-more stringent admissibility requirement in court. As expert witnesses, it is imperative that interpretation is driven by the use of relevant and robust data. This paper has attempted to set out an approach that illustrates the logical use of data to assess a likelihood ratio as a measure of the value of evidence provided by this aspect of anatomy.

Open Access This article is distributed under the terms of the Creative Commons Attribution License which permits any use, distribution, and reproduction in any medium, provided the original author(s) and the source are credited.

\section{References}

1. Sam AH, Sam JTH (2011) Rapid medicine. Wiley, London

2. Bauer J, Curtin JA, Pinkel D, Bastian BC (2007) Congenital melanocytic nevi frequently harbour NRAS mutations but no BRAF mutations. J Investig Dermatol 127:179-182

3. Buxton PK, Morris-Jones R (2009) ABC of dermatology, 5th edn. Blackwell, Chichester

4. Krowchuk DP, Tunnessen WW (2006) In: McMillan JA, Geigin $\mathrm{RD}$, DeAngelis CD, Jones MD (eds) Oski's pediatrics: Principles and practice, 4 th edn. Lippincott, Philadelphia

5. Tannous ZS, Mihm MC, Sober AJ, Duncan LM (2005) Congenital melanocytic nevi: clinical and histopathologic features, risk of melanoma and clinical management. J Am Acad Dermatol $52: 197-203$

6. Rajendran R (2009) Benign and malignant tumors of the oral cavity. In: Rajendran R, Sivapathasundharam B (eds) Shafer's textbook of oral pathology, 6th edn. Elsevier, Noida

7. Tripp JM, Kopf AW (2004) Dysplastic nevus (atypical mole). In: Marghoob AA, Braun RP (eds) Atlas of dermoscopy. Taylor and Francis, London

8. Melanomas. National Cancer Institute. http://www.cancer.gov/ cancertopics/types/melanoma. Accessed September 2012

9. Melanoma Foundation. http://www.melanomafoundation.org/ prevention/abcd.htm. Accessed September 2012

10. Green A, Swerdlow AJ (1989) Epidemiology of melanocytic nevi. Epidemiol Rev 11:204-221

11. Rampen FH, Fleuren BA, DeBoo TM, Lemmens WA (1988) Prevalence of common 'acquired' melanocytic nevi and dysplastic nevi is not related to ultraviolet exposure. J Am Acad Dermatol 18:679-683

12. Darlington S, Siskind V, Green L, Green A (2002) Longitudinal study of melanocytic nevi in adolescents. J Am Acad Dermatol $46: 715-722$
13. Harrison SL, Buettner PG, MacLennan R (1999) Body-site distribution of melanocytic nevi in young Australian children. Arch Dermatol 135:47-52

14. Johr RH, Schachner LA (2002) Nevocellular (melanocytic) nevi. In: Finberg L, Kleinman RE (eds) Saunders manual of pediatric practice. Saunders, Philadelphia

15. Bataille V, Snieder H, MacGregor AJ, Sadieni P, Spector TD (2000) Genetics of risk factors for melanoma: an adult twin study of nevi and freckles. J Natl Cancer Inst 93:457-463

16. Carton J, Daly R, Ramani P (2007) Clinical pathology. Oxford University Press, Oxford

17. Nicholls EM (1973) Development and elimination of pigmented moles and the anatomical distribution of primary malignant melanoma. Cancer 32:191-195

18. Kennedy C, Bajdik CD, Willemze R, De Gruijl FR, Bouwes Vavinck JN (2003) The influence of painful sunburns and lifetime sun exposure on the risk of actinic keratoses, seborrheic warts, melanocytic nevi, atypical nevi and skin cancer. J Investig Dermatol 120:1087-1093

19. Green A, Siskind V, Green A (1995) The incidence of melanocytic nevi in adolescent children in Queensland, Australia. Melanoma Res 5:155-160

20. English DR, Armstrong BK (1994) Melanocytic nevi in children: 1. Anatomic sites and demographic and host factors. Am J Epidemiol 139:390-401

21. Ferri FF (2009) Ferri's color atlas and text of clinical medicine. W.B. Saunders, Philadelphia

22. Avram MR, Tsao S, Tannous Z, Avram MM (2007) Color atlas of cosmetic dermatology. McGraw-Hill, Ohio

23. Barnhill RL (2004) Circumscribed pigmented lesions composed of vasilar melanocytes. In: Barnhill RL, Piepkorn M, Busam KJ (eds) Pathology of melanocytic nevi and malignant melanoma. Springer, Canada

24. Akdeniz Y (2008) Internet child pornography and the law: National and international responses. Ashgate Publishing, Surrey

25. Radford L, Corral S, Bradley C, Fisher H, Bassett C, Howat N, Collishaw S. Child Abuse and Neglect in the UK Today. NSPCC report. Available from: http://www.nspcc.org.uk/Inform/research/ findings/child_abuse_neglect_research_PDF_wdf84181.pdf. Accessed September 2012

26. Calder MC (2004) Child sexual abuse and the Internet: Tackling the new frontier. Russell House Publishing, London

27. Taylor ME (2006) Quayle, child pornography: An Internet crime. Routledge, London

28. Powell A (2007) Paedophiles, child abuse and the Internet. Radcliffe, London

29. Davidson J, Gottschalk P (2011) Internet child abuse: Current research and policy. Routledge, London

30. Jackson G, Black S (submitted) Use of data to inform expert evaluative opinion in the comparison of hand images - the importance of scars. Int J Leg Med. doi:10.1007/s00414-013-0828-5

31. Association of Forensic Science Providers (2009) Standards for the formulation of evaluative forensic science expert opinion. Sci Justice 49:161-164

32. Curran JM, Buckleton JS, Triggs CM, Weir BS (2002) Assessing uncertainty in DNA evidence caused by sampling effects. Sci Justice 42:29-37

33. Aitken CGG (1991) Populations and samples. In: Aitken CGG, Stoney DA (eds) The use of statistics in forensic science. Ellis Horwood, Chichester, pp 51-82

34. Barstow AL (1994) Witchcraze: A new history of the European witch hunts. Harper Collins, London

35. Law Commission. Expert evidence in criminal proceedings in England and Wales. http://www.official-documents.gov.uk/ document/hc1011/hc08/0829/0829.pdf. Accessed September 2012 